\title{
PASI Focuses on Advanced Neural Prostheses \\ http://web.austral.edu.ar/cienciasBiomedicas-programas-32.asp
}

A Pan American Advanced Study Institute (PASI) on "Science and Technology for Advanced Neural Prostheses" will be held in the Hospital Austral in the City of Pilar, Province of Buenos Aires in Argentina on August 3-13, 2009. The PASI will focus on three themes critical to the development of advanced neural prostheses that can make a major impact on improving the way of life, namely (1) a retinal prosthetic device to restore sight to people blinded by inherited degeneration of retina photoreceptors; (2) a cochlear prosthesis to restore hearing to people impaired by degeneration of the natural sound sensors in the cochlea; and (3) sensory nerve stimulators for restoration of motor function in people paralyzed by traumatic nerve degeneration. The PASI will include lectures and invited talks by leading experts in the interdisciplinary fields relevant to the theme of the PASI, and contributed talks and posters presented by students and postdoctoral fellows. Students and postdoctoral candidates wishing to attend this PASI should consult the Web site at http://web.austral.edu. ar/cienciasBiomedicas-programas-32.asp. More information can be obtained by contacting María del Carmen Gómez Diégues, e-mail mcgomez@cas.austral.edu.ar; or Gabriela Monti, e-mail Gmonti@cas.austral. edu.ar; tel. 02322-482572/2574/2980.
A limited number of scholarships will be available to help cover transportation and living expenses. The selection of candidates for the scholarships will be done on the basis of their curriculum vitae and letters or recommendation by advisors. The application deadline is July 1 .

The PASI is sponsored by the U.S. National Science Foundation and the U.S. Department of Energy, and endorsed by the Materials Research Society.

ORLANDO AUCIELLO Director, PASI

Materials Science Division and Center for Nanoscale Materials Argonne National Laboratory

\section{LIBRARY}

The following recently published books, relevant to materials research, have come to MRS Bulletin's attention. Some of the books listed here may be reviewed in future issues of MRS Bulletin. To review a book from the list or to offer recommendations of additional books, contact Editorial Assistant, MRS Bulletin, 506 Keystone Drive, Warrendale, PA 15086-7573, USA; e-mail bulletin@mrs.org.

\section{Books}

A Group-Theoretical Approach to Quantum Optics: Models of Atom-Field Interactions, Andrei B. Klimov and Sergei M. Chumakov, Wiley, 2009, 331 pp., \$190.00,

ISBN: 978-3-527-40879-5.

Advanced Condensed Matter Physics, Leonard M. Sander, Cambridge University Press, 2009, 286 pp., \$80.00, ISBN: 978-0-521-87290-4.

Annual Review of Nano Research, Volume 2, Guozhong Cao and C. Jeffrey Brinker, Editors, World Scientific, 2008, 676 pp., \$98.00,

ISBN: 978-981-279-023-1.

Biofuels, Wim Soetaert and Erik Vandamme, Editors, Wiley, 2009, 256 pp., \$130.00, ISBN: 978-0-470-02674-8.

Bulk Nanostructured Materials, Michael J. Zehetbauer and Yuntian Theodore Zhu, Editors, Wiley, 2009, 736 pp., \$290.00, ISBN: 978-3-527-31524-6.

Chemical Processes with Participation of Biological and Related Compounds, T.M. Lomova and G.E. Zaikov, Editors, Brill Academic, 2008, 422 pp., \$238.00, ISBN: 978-90-04-16210-5.
Chirality at the Nanoscale: Nanoparticles, Surfaces, Materials and More, David B. Amabilino, Editor, Wiley, 2009, 440 pp. \$210.00, ISBN: 978-3-527-32013-4.

CVD Diamond for Electronic Devices and Sensors, Ricardo S. Sussmann, Editor, Wiley, 2009, 596 pp., \$250.00, ISBN: 978-0-470-06532-7.

Dynamics and Relativity, Jeffrey Forshaw and Gavin Smith, Wiley, 2009, 338 pp., $\$ 60.00$ ISBN: 978-0-470-01460-8

Electrocorrosion and Protection of MetalsGeneral Approach with Particular Consideration to Electrochemical Plants, Joseph Riskin, Elsevier, 2009, 264 pp., \$165.00, ISBN: 978-0-444-53295-4.

Handbook of Ring-Opening Polymerization, Philippe Dubois, Olivier Coulembier, and Jean-Marie Raquez, Editors, Wiley, 2009, 425 pp., \$215.00, ISBN: 978-3-527-31953-4.

High Performance Pigments, 2nd Edition, Edwin B. Faulkner and Russell J. Schwartz, Editors, Wiley, 2009, 538 pp., \$230.00, ISBN: 978-3-527-31405-8.

Injection Molding: Fundamentals and Applications, Musa R. Kamal, Avram Isayrev, and Shih-Jung Miu, Editors, Hanser Gardner Publications, 2009, 800 pp., \$249.00, ISBN: 978-1-56990-434-3.

Low Temperatures and Cold Molecules, Ian W.M. Smith, Editor, Imperial College Press, 2008, 580 pp., $\$ 128.00$, ISBN: 978-1-84816-209-9.

Materials Innovations in an Emerging Hydrogen Economy: Ceramic Transactions, G. Wicks and Jack Simon, Editors, Wiley, 2009, 256 pp., \$125.00, ISBN: 978-0-470-40836-0.
Microfabricated Power Generation Devices: Design and Technology, Alexander Mitsos and Paul I. Barton, Editors, Wiley, 2009, 300 pp., \$215.00, ISBN: 978-3-527-32081-3.

Mixing and Compounding of Polymers, 2nd Edition, I. Manas-Zloczower, Hanser Gardner Publications, 2009, 850 pp., \$249.00, ISBN: 978-1-56990-424-4

Nanotechnology: Volume 6: Nanoprobes, Harald Fuchs, Editor, Wiley, 2009, 388 pp. \$215.00, ISBN: 978-3-527-31733-2.

Nuclear and Particle Physics: An Introduction, 2nd Edition, Brian Martin, Wiley, 2009, 454 pp., $\$ 70.00$,

ISBN: 978-0-470-74275-4

Properties of Polymers: Their Correlation with Chemical Structure; Their Numerical Estimation and Prediction from Additive Group Contributions, D.W. van Krevelen and Klaas te Nijenhuis, Elsevier, 2009, 1030 pp., \$365.00, ISBN: 978-0080548197.

Quantum Mechanics: Concepts and Applications, 2nd Edition, Nouredine Zettili, Wiley, 2009, 688 pp., \$200.00,

ISBN: 978-0-470-02678-6.

Smart Light-Responsive Materials: Azobenzene-Containing Polymers and Liquid Crystals, Y. Zhao and Tomiki Ikeda, Editors, Wiley, 2009, 514 pp., \$140.00, ISBN: 978-0-470-17578-1.

Spectroscopy of Low Temperature Plasma, Vladimir N. Ochkin, Wiley, 2009, 630 pp., \$230.00, ISBN: 978-3-527-40778-1.

Update on Medical Plasticised PVC, Xiaobin Zhao, Rapra Publishing, 2009, \$135.00, ISBN: 978-1-84735-208-8. 